\title{
Implementation and Feasibility of Electronic Patient-Reported Outcome (ePRO) Data Entry in the PRAEGNANT Real-Time Advanced and Metastatic Breast Cancer Registry
}

\section{Evaluation einer elektronischen Erhebung von Patient-reported- Outcomes (PROs) im PRAEGNANT-Register}

Authors

Markus Wallwiener ${ }^{*}$, Felix Heindl ${ }^{2}$, Sara Y. Brucker ${ }^{3}$, Florin-Andrei Taran ${ }^{3}$, Andreas Hartkopf ${ }^{3}$, Friedrich Overkamp ${ }^{4}$, Hans-Christian Kolberg ${ }^{5}$, Peyman Hadji ${ }^{6}$, Hans Tesch ${ }^{7}$, Johannes Ett ${ }^{8}$, Michael P. Lux ${ }^{2}$, Claudia Rauh ${ }^{2}$, Simon Blum², Naiba Nabieva², Tobias F. Brodkorb², Cornelia Faschingbauer ${ }^{2}$, Hanna Langemann², Carla Schulmeyer ${ }^{2}$, Bernhard Volz ${ }^{2}$, Matthias Rübner ${ }^{2,9}$, Diana Lüftner ${ }^{10}$, Volkmar Müller ${ }^{11}$, Erik Belleville ${ }^{12}$, Wolfgang Janni ${ }^{13}$, Tanja N. Fehm ${ }^{14}$, Diethelm Wallwiener $^{3}$, Thomas Ganslandt ${ }^{15}$, Matthias W. Beckmann², Andreas Schneeweiss ${ }^{1,16}$, Peter A. Fasching ${ }^{2}$, Paul Gass ${ }^{2}$

\section{Affiliations}

1 Department of Obstetrics and Gynecology, University of Heidelberg, Heidelberg, Germany

2 Department of Gynecology and Obstetrics, Erlangen University Hospital, Comprehensive Cancer Center Erlangen-EMN, Friedrich-Alexander University of Erlangen-Nuremberg, Germany

3 Department of Obstetrics and Gynecology, University of Tübingen, Tübingen, Germany

4 Outpatient Department of Hematology and Oncology, Recklinghausen, Germany

5 Marienhospital Bottrop, Bottrop, Germany

6 Nordwest Hospital, Frankfurt, Germany

7 Onkologie Bethanien, Frankfurt, Germany

8 Department of Obstetrics and Gynecology, Technical University of Munich, Munich, Germany

9 Institut für Frauengesundheit (IFG), Erlangen, Germany

10 Department of Hematology, Oncology and Tumor Immunology, Charité University Hospital, Berlin, Campus Benjamin Franklin, Berlin, Germany

11 Department of Gynecology, Hamburg-Eppendorf University Medical Center, Hamburg, Germany

12 Clin-Sol Ltd., Würzburg, Germany

13 Department of Gynecology and Obstetrics, Ulm University Hospital, Ulm, Germany

14 Department of Gynecology and Obstetrics, Heinrich Heine University of Düsseldorf, Düsseldorf, Germany

15 Chair of Medical Informatics, Friedrich-AlexanderUniversity Erlangen-Nuremberg, Erlangen, Germany

16 National Center for Tumor Diseases and Department of Gynecology and Obstetrics, Heidelberg University Hospital, Heidelberg, Germany

Key words

breast cancer, patient-reported outcomes, electronic data capture, compliance, quality of life
Schlüsselwörter

Brustkrebs, Patient-reported Outcomes, Electronic Data

Capture, Compliance, Lebensqualität

received $\quad 31.5 .2017$

revised 9.7.2017

accepted 9.7.2017

Bibliography

DOI https://doi.org/10.1055/s-0043-116223

Geburtsh Frauenheilk 2017; 77: 870-878 @ Georg Thieme

Verlag KG Stuttgart · New York | ISSN 0016-5751

Correspondence

Peter A. Fasching, MD

Erlangen University Hospital, Department of Gynecology and Obstetrics, Comprehensive Cancer Center Erlangen EMN,

Friedrich Alexander University of Erlangen-Nuremberg Universitätsstraße 21-23, 91054 Erlangen, Germany peter.fasching@uk-erlangen.de

\section{ABSTRACT}

Purpose Patient-reported outcomes (PROs) have been incorporated into clinical trials for many symptoms and medical conditions. A transition from paper-based capture of PROs to electronic PROs (ePROs) has recently started. This study reports on the feasibility of ePRO assessment in a prospective registry including molecular data for patients with advanced breast cancer.

Methods As part of the PRAEGNANT network, patients were invited by clinical trial staff, physicians, and nurses to complete three standardized Internet-based questionnaires (EQ 5D $5 \mathrm{~L}, \mathrm{CES}-\mathrm{D}$ and IPAQ). Feasibility was assessed by the staff

* Shared first authorship 
members who assigned the user accounts by the patients. The completeness of the questionnaires was also assessed.

Results Fifteen of 17 patients who were asked agreed to participate to complete the PRO questionnaires (EQ-5D-5L and CES-D). However, the IPAQ (physical activity) questionnaire was only validly completed by 9 patients. Feasibility was ranked better by the physicians and dedicated clinical trial staff than by the nursing staff.

Conclusions Incorporating ePRO questionnaires into an advanced breast cancer registry is feasible, and no major hurdles were reported. Involving stakeholders from the start, the application is tailored to the capacities and abilities of both patients and clinical staff. The patients' compliance was better with some questionnaires, but others may present difficulties.

\section{ZUSAMMENFASSUNG}

Hintergrund Das PRAEGNANT-Netzwerk ist ein prospektives translationales Forschungskonzept zur Optimierung der gesundheitlichen Versorgung von Patientinnen mit lokal fortgeschrittenem oder metastastiertem Brustkrebs. Patient-reported outcomes (PROs) wurden in vielen klinischen Studien aufgenommen. Zunehmend geht es von der analogen Erhebung auf Papier (pPRO) in die elektronische Erhebung (ePRO) über. Dieses Subprotokoll der PRAEGNANT soll die Implementierung und Machbarkeit dieses neuen Vorgehens evaluieren. Methoden Die Patientinnen wurden von dem Personal der Studienzentrale, dem ärztlichen oder dem pflegerischen Personal am Brustzentrum Franken des Universitätsklinikums Erlangen, gebeten, 3 standardisierte Fragebögen zum PROs (EQ-5D-5L, CES-D und IPAQ) elektronisch auszufüllen. Anschließend wurde die Bedienbarkeit und Zufriedenheit der Patientinnen und die Benutzerfreundlichkeit zur Vergabe der Zugangsdaten von den 3 Personalgruppen abgefragt.

Ergebnisse Fünfzehn von 17 eingeschlossenen Patientinnen füllten abschließend die 2 ePRO-Fragebögen (EQ-5D-5L und CES-D) aus. Der elektronische Fragebogen zur körperlichen Aktivität (IPAQ) konnte von 9 der 15 Patientinnen erhoben werden. Machbarkeit zur Benutzerdatenvergabe wurde absteigend von den Ärzten gegenüber dem Studienzentralenpersonal und Pflegepersonal als besser bewertet.

Schlussfolgerung Die Benutzung der ePRO-Fragebögen ist in der PRAEGNANT Registry grundsätzlich durchührbar. Die Machbarkeit hängt maßgeblich von den Fähigkeiten und Kapazitäten der beteiligten Patientinnen und Personalgruppen ab. Die Compliance und Vollständigkeit war nicht bei allen ePROFragebögen gleich gut und ergab teilweise Schwierigkeiten.

\section{Introduction}

Over the last 10 years, it has been growing increasingly important to take patients' well-being into account and to assess the effects of treatment on their quality of life. The development of novel therapies and new diagnostic tools have altered treatment approaches in both early and advanced breast cancer. Modern molecular tests have now made it possible to identify women who are unlikely to benefit from chemotherapy, as they have a favorable prognosis [1,2]. In addition, the development of new drugs has led to new drug toxicity profiles that are rarely seen in patients receiving conventional chemotherapy or antihormonal therapy [3]. Examples of these include treatment with mechanistic target of rapamycin (mTOR) inhibitors, which is associated with clinically relevant stomatitis [4], and phosphoinositide 3-kinase (PI3K) inhibitors, with some a dose-limiting toxicity has been found to involve psychiatric disorders [5]. It is therefore becoming more and more important to register the side effects of drugs and the patients' quality of life as accurately as possible and to include several methods of measuring these $[6,7]$. This study reports on the methods used to incorporate reporting of specific patient-reported outcomes (PROs) into a real-time registry including molecular data for patients with advanced breast cancer.

Adverse events and specific symptoms are common in patients with advanced breast cancer, but they are not always detected in clinical routine work or in clinical trials $[8,9]$. Capturing data on treatment outcomes and quality of life for advanced breast cancer patients during clinical routine work and in clinical trials is challenging. The paper-based methods currently used for recording PROs require costly staff resources, and they may lead to the patients' point of view being underrepresented. With the growing demand for better information provision and communication with patients, on the one hand, and the increasing use of information technology by health-care providers on the other, the potential for developing "eHealth" solutions in health-care research is becoming increasingly clear [10].

In closely related areas such as research on health-related quality of life (HRQoL), satisfaction with care, and drug adherence, PROs are already a standard method of collecting data [11-13]. The Food and Drug Administration (FDA) in the United States has therefore issued draft guidance for the pharmaceutical industry establishing PRO measures as a standard for evaluating symptom end points [14]. The feasibility of direct symptom reporting by patients - even those with terminal cancer and a severe symptomatic burden - has been shown in several studies $[13,15,16]$.

In addition, the assessment of adverse events by health-care professionals may be subject to considerable interobserver variation [17]. In this context, PROs are substantially more reliable and practicable. Most patients are willing and able to self-report their experience of treatment [18]. In the United States, a recent study of the Patient-Reported Outcomes version of the Common Terminology Criteria for Adverse Events (PRO-CTCAE) reported that the tool had favorable validity, reliability, and responsiveness [19].

More and more PRO surveys are being used in routine outpatient cancer care. Current data show that among breast cancer patients, there was a high level of monthly compliance with completing questionnaires at home using Internet-based reporting justifying strategies for enhancing compliance in routine care settings [16].

In particular, it has also been reported that patient self-reporting via web-connected devices during routine chemotherapy care at clinic visits is feasible, with a high level of patient satisfaction 


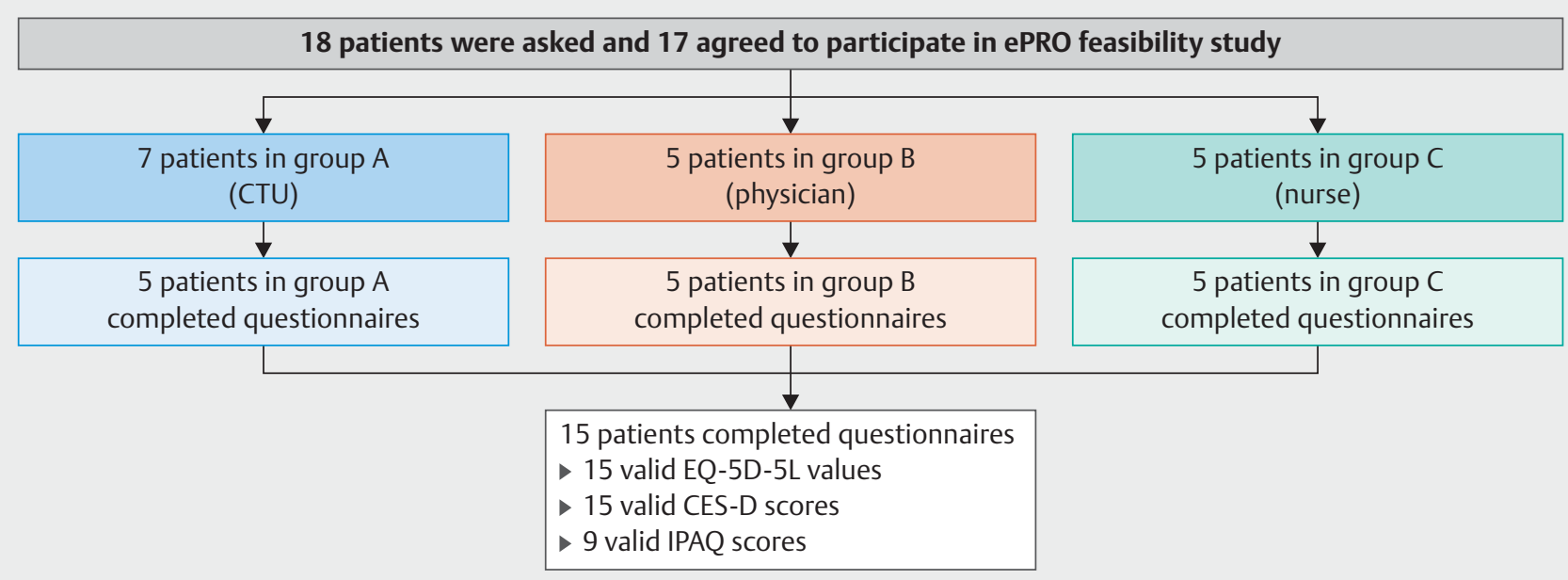

- Fig. 1 Flowchart for patient selection in the PRAEGNANT-PRO subprotocol. CES-D, Center for Epidemiological Studies of Depression; EQ-5D-5L, European Quality of Life Five Dimensions, Five Levels; IPAQ, International Physical Activity Questionnaire.

and good usability with the systems, even for patients unfamiliar with the Internet and elderly patients [20,21]. Research has been carried out on identifying subgroups of patients who may or may not be willing to use web-based questionnaires. Barriers to ePRO usage were identified in particular in older patients and subgroups with a poorer quality of life [22].

Basch et al. have recently described qualitative and quantitative differences between the PRO-CTCAE and classic HRQoL surveys. Qualitatively, the PRO data captured with the PRO-CTCAE have greater depth and less scattered detail. The PRO-CTCAE is also intended for continuous everyday use, in comparison with the before-after comparisons recorded using the HRQoL [23].

Our research group recently established a real-time registry including molecular data for patients with advanced breast cancer [24]. In view of the extensive published data reporting the advantages of electronic capture of PROs, the aims of the present study were to assess the feasibility of using dedicated study staff to initiate patient data entry; to investigate the patients' own views on the feasibility of the process; and to assess the quality of the patient-reported outcome data.

\section{Methods}

\section{The PRAEGNANT network and the PRO subprotocol}

The PRAEGNANT network is a real-time registry including molecular data for patients with advanced breast cancer [24] that serves not only to collect and analyze data, but also as a health-care tool for identifying patients who may be eligible for inclusion in clinical trials [25]. The present study is based on a subprotocol within the main study, focusing on the implementation of electronic capture of three different validated questionnaires. In order to assess feasibility in the clinical setting, three different groups of staff were involved in including patients in the study and explaining to them how to fill out the electronic forms. The study was designed to be completed when five patients for each staff group had logged into the electronic data capture system. The three designated groups were:

1. the dedicated clinical trial unit (CTU) staff, trained to carry out documentation in the PRAEGNANT network;

2. the resident physicians treating the patients; and

3. the nurses involved in actual cancer care and treatment.

\section{Procedures for patient inclusion and data capture}

After being included in the main PRAEGNANT study, patients were asked whether they would be willing to take part in the PRAEGNANT-PRO subproject. A total of 18 patients were asked at study entry, one patient had to be excluded because of withdrawal of informed consent and 17 of 18 patients agreed to complete three validated questionnaires through the study's remote data entry system ( $\triangleright$ Fig. 1 ). The patients were provided with two links: one leading to a form for changing their individual login credentials and one for logging on to the data capture dashboard to access the questionnaires ( $\bullet$ Fig. 2 ). After logging on to the system, the patients then had to select the relevant form to proceed to the questions ( $\triangleright$ Fig. 2). The order in which the questionnaires were displayed was:

1. the European Quality of Life Five Dimensions, Five Levels (EQ5D-5L) scale for health status;

2. the Center for Epidemiological Studies of Depression (CES-D) scale for depression status; and

3. the International Physical Activity Questionnaire (IPAQ) for physical activity.

After completing their data entry, the patients had to click on "Save" to submit the results. Optional "on-site completion" (completing the questionnaires on a computer at the hospital) was provided for patients who did not have devices available at home. 


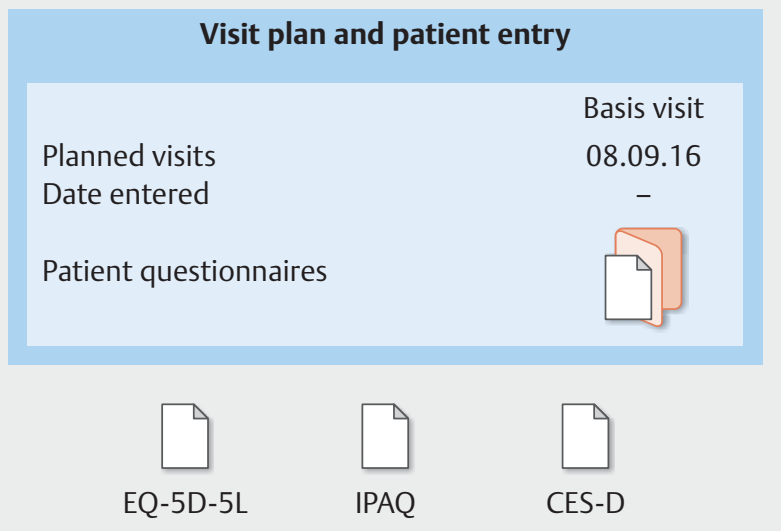

- Fig. 2 The patient data entry form (translated from the German version).
- Table 1 Participants and tumor characteristics.

\begin{tabular}{|l|c|c|c|}
\hline Characteristics & $\begin{array}{l}\text { Total (n) } \\
\text { or mean }\end{array}$ & $\begin{array}{l}\text { \% or } \\
\text { SD }\end{array}$ & Range \\
\hline Age (years) & 56.9 & 14 & $38-79$ \\
\hline BMI (kg/m²) & 22.8 & 4.3 & $16-31$ \\
\hline Treatment & & & \\
\hline - First-line & 7 & 47 & \\
\hline - Second-line & 4 & 27 & \\
\hline - Third-line & 1 & 6 & \\
\hline - Locally advanced & 3 & 100 & \\
\hline - Total & 15 & & \\
\hline Computer/smartphone/ & & 67 & \\
\hline tablet usage pattern & & 13 & \\
\hline - Daily & 10 & 20 & \\
\hline - At least once a week & 2 & 100 & \\
\hline - Never & 3 & & \\
\hline - Total & 15 & & \\
\hline
\end{tabular}

systematic data queries, the datasets are additionally anonymized.

\section{Statistical considerations}

The patient characteristics, feasibility questions, and EQ-5D-5L QoL data recorded are presented as means and standard deviations (SD) for continuous variables and as absolute and relative frequencies for categorical variables. For quality control purposes, age, body mass index (BMI), and the scores in the questionnaires used were tested for associations using Spearman's correlation coefficient. Differences in feasibility assessments by the staff group were tested using the Kruskal-Wallis test. All statistical analyses and summary statistics were carried out using IBM SPSS Statistics, version 21.0 (IBM Corporation, Armonk, New York, USA).

\section{Results}

\section{Patient demographics and technical skills}

Fifteen of the 17 patients who agreed to take part in this feasibility study completed at least part of one questionnaire. The study was designed in such a way that for each of three groups - physicians, nurses, and dedicated study personnel - exactly five patients were to complete the questionnaire ( $\bullet$ Fig. 1 ). Data are presented here for the 15 patients who completed the questionnaire. Only data from the feasibility questionnaire addressed to the clinical staff are reported for the set of all 17 user account assignments.

The patients' mean age was 56.9 years ( \pm 14 years) and their mean BMI was $22.8 \mathrm{~kg} / \mathrm{m}^{2}\left( \pm 4.3 \mathrm{~kg} / \mathrm{m}^{2}\right)$. Almost half of the patients were included before the start of first-line treatment in the advanced therapy setting $(n=7,47 \%)$. At the time when they were included in the ePRO PRAEGNANT study, most of the patients stated that they used a computer, tablet, or smart phone daily or at least once a week $(n=12,80 \%)$. The patient characteristics are listed in $\boldsymbol{\sim}$ Table 1. 
- Table 2 Line listing of patients.

\begin{tabular}{|c|c|c|c|c|c|c|c|}
\hline Patient & Age & Group & Treatment situation & $\begin{array}{l}\text { EQ-5D-5L } \\
\text { profile }\end{array}$ & $\begin{array}{l}\text { EQ-5D-5L } \\
\text { index }{ }^{\#}\end{array}$ & $\begin{array}{l}\text { IPAQ } \\
\text { METs/week }\end{array}$ & $\begin{array}{l}\text { CES-D } \\
\text { score }\end{array}$ \\
\hline 1 & 60 & Physicians & Second-line & 31333 & 0.788 & 0 & 26 \\
\hline 2 & 39 & Physicians & First-line & 42533 & 0.376 & Removed* & 33 \\
\hline 3 & 67 & Nurses & Second-line & 21121 & 0.828 & 2415 & 12 \\
\hline 4 & 79 & Nurses & Second-line & 31112 & 0.900 & 5742 & 10 \\
\hline 5 & 68 & Physicians & First-line & 11121 & 0.910 & 1188 & 19 \\
\hline 6 & 46 & Nurses & Locally advanced & 11113 & 0.999 & 1548 & 31 \\
\hline 7 & 84 & CTU & First-line & Missing & Missing & Missing & Missing \\
\hline 8 & 75 & Nurses & Third-line & 35232 & 0.291 & 1782 & 19 \\
\hline 9 & 50 & Physicians & First-line & 21224 & 0.637 & Removed** & 35 \\
\hline 10 & 60 & CTU & Second-line & 14433 & 0.620 & 2772 & 33 \\
\hline 11 & 55 & Physicians & First-line & 21343 & 0.595 & Removed** & 18 \\
\hline 12 & 30 & CTU & First-line & Missing & Missing & Missing & Missing \\
\hline 13 & 66 & CTU & First-line & 43354 & 0.127 & 982 & 36 \\
\hline 14 & 72 & CTU & First-line & 31241 & 0.578 & Missing & 24 \\
\hline 15 & 41 & CTU & First-line & 31322 & 0.810 & 2772 & 24 \\
\hline 16 & 40 & Nurses & Locally advanced & 11131 & 0.887 & Removed** & 21 \\
\hline 17 & 38 & CTU & Locally advanced & 11113 & 0.999 & Removed** & 18 \\
\hline
\end{tabular}

CES-D, Center for Epidemiological Studies of Depression (scale); CTU, clinical trials unit staff; EQ-5D-5L, European Quality of Life Five Dimensions, Five Levels (scale); IPAQ, International Physical Activity Questionnaire; MET, metabolic equivalent of task.

* Patient stated that he did less than 10 min exercise weekly and had to be removed in accordance with IPAQ analysis guidelines.

** Patients stated that they did more than 960 min exercise weekly.

\# Calculated with reference to Germany.

- Table 3 Correlation between selected parameters for quality control purposes, showing Spearman correlation coefficients and numbers of patients for correlation $\rho(n)$. One of the correlations was statistically significant (IPAQ MET/week versus CES-D, $p=0.049$ ).

\begin{tabular}{|l|l|r|r|r}
\hline & BMI & EQ-5D-5L index & \multicolumn{1}{|l}{ IPAQ } & \multicolumn{1}{c|}{ CES-D score } \\
\hline Age & & & $0.130(12)$ & $-0.296(15)$ \\
\hline BMI & $-0.043(15)$ & $-0.232(15)$ & $-0.211(12)$ & $0.498(15)$ \\
\hline EQ-5D-5L index & & $-0.306(15)$ & $0.172(12)$ & $-0.448(15)$ \\
\hline IPAQ MET/week & & & & $-0.577(12)$ \\
\hline
\end{tabular}

BMI, body mass index; CES-D, Center for Epidemiological Studies of Depression (scale); EQ-5D-5L, European Quality of Life Five Dimensions, Five Levels (scale); IPAQ, International Physical Activity Questionnaire; MET, metabolic equivalent of task.

\section{Patient reported outcome data}

The individual results for the participating patients are shown in - Table 2. All of the 15 patients completed the EQ-5D-5L questionnaire; the IPAQ was completed by 14 patients; and the CES-D was completed by all 15 . The IPAQ results from five patients had to be removed, as the patients stated that they spent either less than 10 minutes $(n=1)$ or more than 960 minutes per week $(n=4)$ in physical activity, and these values are regarded as outliers in the IPAQ guidelines for data processing and analysis [26]. As one patient did not complete the IPAQ questionnaire, there were only nine patients for whom valid metabolic equivalents of task (METs) per week could be calculated. The EQ-5D-5L index values (calculated with reference to Germany population) ranged from 0.127 to 0.999 , the IPAQ METs/week ranged from 0 to 5742 , and the CES-D scores ranged from 10 to 36 ( $\vee$ Table 2 ).

For quality control purposes, age and BMI were correlated with the results of the questionnaires. Although only one correlation was statistically significant (IPAQ METs/week versus CES-D, $n=12, p=0.049$ ), there were negative correlations between BMI and IPAQ $(\rho=-0.211)$ and between age and CES-D $(n=15$, $\rho=-0.296$ ). It should be noted that there was no correlation between age and BMI in this small group of participants ( $\triangleright$ Table 3 ). 
- Table 4 Results of the feasibility questionnaire among staff.

\begin{tabular}{|c|c|c|c|}
\hline Question & $\begin{array}{l}\text { n or } \\
\text { mean }\end{array}$ & $\begin{array}{l}\% \text { or } \\
\text { SD }\end{array}$ & Range \\
\hline $\begin{array}{l}\text { Time needed to assign } \\
\text { patient access to the system }\end{array}$ & 12.94 & 11.6 & $5-45$ \\
\hline \multicolumn{4}{|l|}{$\begin{array}{l}\text { Difficulty of assigning patient } \\
\text { access }\end{array}$} \\
\hline - 1 (very easy) & 7 & 41 & \\
\hline .2 & 6 & 35 & \\
\hline .3 & 3 & 12 & \\
\hline .4 & 2 & 12 & \\
\hline - 5 (very difficult) & 0 & & \\
\hline - Total & 17 & 100 & \\
\hline \multicolumn{4}{|l|}{$\begin{array}{l}\text { Problems with assigning } \\
\text { patient access }\end{array}$} \\
\hline - No & 10 & 59 & \\
\hline - Yes & 7 & 41 & \\
\hline - Total & 17 & 100 & \\
\hline \multicolumn{4}{|l|}{$\begin{array}{l}\text { Will the patient be using } \\
\text { a device in the hospital } \\
\text { or at home? }\end{array}$} \\
\hline - At home & 14 & 82 & \\
\hline - In the hospital & 3 & 18 & \\
\hline - Total & 17 & 100 & \\
\hline
\end{tabular}

\section{Feasibility analysis of clinical staff}

With regard to the assessment by the clinical staff of the feasibility of assigning data accounts to the patients ( $\bullet$ Table 4 ), most of the hospital personnel stated that it was either easy or very easy ( $n=13,76 \%$ ). None of the participating staff stated that it was very difficult, but two (12\%) described it as difficult. The average time needed to assign the accounts was $13 \mathrm{~min}$ ( $\pm 12 \mathrm{~min}$ ). When the staff groups' assessments of the degree of difficulty of assigning data accounts to patients were compared, it was found that the physicians and dedicated study personnel described it as low, in comparison with higher difficulty levels reported by nurses ( $\triangleright$ Table 5).

\section{Patient preferences regarding paper- versus electronic-based assessment}

When initially asked about their preference, only three patients stated that they wanted to use a hospital device/computer to complete the questionnaires ( $\triangleright$ Table 4). However, seven patients completed the questionnaires in the hospital later on.

With regard to ease of use, most patients stated that they felt comfortable or very comfortable with the ePRO questionnaires ( $n=11,74 \%$ ) ( $\triangleright$ Table 6 ) and rated the questions as being quite easy or very easy to answer $(n=11,74 \%)$. The average time needed to complete the three questionnaires was 15 min (SD $\pm 11 \mathrm{~min}$ ). Five patients stated that they would prefer to use ePRO rather than paper; three patients had no preference with regard to subsequent questionnaires, and seven of fifteen patients in total stated that they would not prefer an electronic questionnaire. Three of these patients, who would prefer pPRO, had no access at home to an electronic device (e.g., a computer, smartphone, or tablet). Only one patient who had access to an electronic device would not want to take part in an ePRO study similar to the PRAEGNANT study if electronic questionnaires were to become mandatory.

\section{Discussion}

The responses from 15 of the 17 patients included show that it appears to be feasible to allow patients to complete standardized electronic questionnaires about quality of life, depression, and physical activity. This is also reflected in the fact that the majority of the patients $(88 \%)$ stated that they were comfortable with completing electronic questionnaires. However, $40 \%$ of the patients who had everyday access to computers $(4 / 10)$ still said they would prefer a paper questionnaire. There do not appear to be any issues involving a potentially lower recruitment rate when electronic questionnaires are offered.

Although electronic self-reporting is increasingly being used in the administration of clinical trials and in other studies [22], there are only limited data about the feasibility of electronic self-reporting for patients and study personnel.

Studies investigating the feasibility of self-reporting via web devices during hospital visits for routine chemotherapy care have reported high mean compliance rates, ranging from 75 to $85 \%$ $[20,21]$. Results published by our own group have also shown that

- Table 5 Feasibility of registering a patient for the electronic patient-reported outcome (ePRO) questionnaires and assigning a user account. Feasibility was assessed using a numbered scale, with 1 representing very easy and 5 very difficult. Figures represent the number of staff assessments. None of the differences were statistically significant ( $p=0.047$, Kruskal-Wallis test).

\begin{tabular}{|l|l|l|l|l|}
\hline Feasibility & Physicians $(\mathbf{n})$ & Nurses $\mathbf{( n )}$ & Clinical trials unit staff (n) & Total \\
\hline 1 (very easy) & 4 & 0 & 3 & 7 \\
\hline 2 & 0 & 3 & 3 & 6 \\
\hline 3 & 0 & 2 & 0 & 2 \\
\hline 4 & 1 & 1 & 0 & 2 \\
\hline 5 (very difficult) & 0 & 0 & 0 & 0 \\
\hline Total & 5 & 6 & 6 & 17 \\
\hline
\end{tabular}


electronic screening provides a time-saving option, with excellent data quality [27].

The implementation of ePRO questionnaires in the PRAEGNANT network is therefore being closely monitored, and the feasibility of the procedure is being assessed as part of a research program. This feasibility study shows that the physicians and trained research staff involved found that the technical process of assigning ePRO accounts to patients was easier than dedicated cancer care nurses perceived it to be. It may be that eHealth facilities need to be addressed for this health-care group as part of future educational programs, or that the development and implementation of eHealth facilities might require completely new health-care personnel. In connection with obstacles to implementation, possible support services for participating nurses might promote willingness, compliance, and elimination of technical hurdles, as this group was found to have reservations regarding ePRO. Several programs concerned with supporting the role of nurses in relation to eHealth are available [28-30].

Although $67 \%(n=10)$ of the patients were daily users of electronic devices (such as computers, smartphones, or tablets), $33 \%$ $(n=5)$ did not use them or used them only infrequently.

Other ePRO applications have been reported to be easily usable and acceptable, even among patients unfamiliar with the Internet and among elderly patients $[20,21]$. Our research group is conducting a trial investigating the willingness of patients with advanced breast cancer to respond to electronic questionnaires. This has shown that patients who would prefer a paper-based survey (PPRO) a priori tend to be older (ePRO 53 years vs. PPRO 62 years; $p=0.0014$ ) and typically have lower educational levels $(p=0.0002)$ and are in poorer health $(p=0.0327)$ [22]. Previous experience with technology also appears to be a key factor, as it was found that there are more ePRO users than PPRO users among the advanced and professional groups ( $n=27,52 \%$ vs. $n=17,6 \%$ ). Willingness to use ePRO in the future was lower among older patients and subgroups of patients who had a poorer quality of life [22]. This is in stark contrast to previously published data and underlines the need for tailored interventions and support services for older, less technologically skilled patients. However, most of the published trials have been based in the United States, which might explain the higher prevalence of users familiar with the technology needed. Overall, randomized PRO trials in oncology have reported that ePRO is well received among patients in comparison with pPRO [31,32]. It can therefore be anticipated that using electronic PRO questionnaires will be feasible in age groups comparable with that in the average breast cancer population.

Although the associations tested between patient characteristics and questionnaire outcomes were only exploratory, serving for quality control purposes, several associations in the expected directions were observed. Age correlated inversely with the depression score, as has also been reported in other studies [3335]. BMI also correlated inversely with METs/week, as has also previously been reported $[36,37]$. There were no correlations between BMI and age in the present study. This might be one reason why there was not an inverse correlation between age and METs/ week [38-40].
- Table 6 Results of the feasibility questionnaire among patients.

\begin{tabular}{|c|c|c|c|}
\hline Question & $\begin{array}{l}\text { n or } \\
\text { mean }\end{array}$ & $\begin{array}{l}\% \text { or } \\
\text { SD }\end{array}$ & Range \\
\hline $\begin{array}{l}\text { Time needed to complete the } \\
\text { three questionnaires (min) }\end{array}$ & 15.2 & 10.5 & $5-40$ \\
\hline \multicolumn{4}{|l|}{$\begin{array}{l}\text { Ease of completing the } \\
\text { questionnaire }\end{array}$} \\
\hline - 1 (very easy) & 6 & 40 & \\
\hline .2 & 5 & 34 & \\
\hline .3 & 2 & 13 & \\
\hline .4 & 2 & 13 & \\
\hline - 5 (very difficult) & 0 & 0 & \\
\hline - Total & 15 & 100 & \\
\hline \multicolumn{4}{|l|}{ Difficulty of questions } \\
\hline - 1 (very easy) & 7 & 47 & \\
\hline .2 & 4 & 27 & \\
\hline .3 & 2 & 13 & \\
\hline .4 & 1 & 7 & \\
\hline - 5 (very difficult) & 1 & 7 & \\
\hline - Total & 15 & 100 & \\
\hline \multicolumn{4}{|l|}{$\begin{array}{l}\text { Preferred form of } \\
\text { questionnaire for next time }\end{array}$} \\
\hline - Paper (pPRO) & $7^{*}$ & 47 & \\
\hline - Electronic (ePRO) & 5 & 33 & \\
\hline - I don't mind & 3 & 20 & \\
\hline - Total & 15 & 100 & \\
\hline \multicolumn{4}{|l|}{$\begin{array}{l}\text { Would using an electronic } \\
\text { questionnaire be a reason } \\
\text { for not taking part in a similar } \\
\text { study in the future? }\end{array}$} \\
\hline - No & 11 & 73 & \\
\hline - Yes & $3^{* *}$ & 20 & \\
\hline - I don't mind & 1 & 7 & \\
\hline - Total & 15 & 100 & \\
\hline \multicolumn{4}{|c|}{$\begin{array}{l}\text { * Three of these patients said they never used a computer/tablet/ } \\
\text { smartphone at all, and four patients stated that they used them daily. }\end{array}$} \\
\hline \multicolumn{4}{|c|}{$\begin{array}{l}\text { ** Two of these patients said they never used a computer/tablet/ } \\
\text { smartphone at all. }\end{array}$} \\
\hline
\end{tabular}

The study has several limitations. Firstly, it is a feasibility assessment in a prospective investigation of the implementation of electronic patient-completed validated ePRO questionnaires. The study thus only has a small sample size, and the EQ-5D-5L, IPAQ, and CES-D values obtained should be treated with caution. However, the ranges do not indicate any outliers or unusual values. The IPAQ questionnaires produced valid MET calculations in only nine cases. Although the questionnaire has only been validated for patients up to the age of 69 and the present patient group included had three participants over that age, one of the three did not start the IPAQ at all and the other two did not enter any data in it, resulting in elimination of the calculated MET data. Another reason for the exclusion of these IPAQ values was the question- 
naire's guidelines for data processing and analysis, which provide rules for excluding outliers [26]. However, the five patients who had to be removed from the IPAQ scoring were contacted and the extent of weekly physical activity was confirmed in one patient.

Future research will need to address the issue of differences between the groups of patients who prefer electronic assessment and those who prefer nonelectronic assessment. The importance of this lies in the need to understand the difference between these preference groups and whether their responses to PPRO or ePRO questionnaires would be discordant. It might also be possible that the same patient might choose different responses to the same question, depending on whether the recording method is ePRO or PPRO - perhaps in connection with assessing mood or depression. Although the patients needed an average of about 15 minutes to complete each of the three questionnaires, many studies have included additional PRO questionnaires to assess and monitor the complex area of HRQoL. For longitudinal data capture, ePRO applications might be superior to link-based platforms regarding patient adherence. Future studies will therefore need to focus also on the quality of data relative to the time needed to complete the questionnaire and relative to potential bias resulting from the order in which the questionnaires are displayed and answered.

\section{Conclusions}

Overall, the study shows that it appears to be feasible to use data entered electronically by patients themselves to register patientreported outcomes in an advanced breast cancer registry. No major problems occurred and no major hurdles were reported. One aim of the study was to make the implementation process more transparent, in order to enable other researchers to retain crucial elements of it when implementing ePRO in other oncological settings. Involving stakeholders from the start, the application is tailored to the capacities and abilities of both patients and clinical staff. The patients' compliance was better with some questionnaires, but others may present difficulties.

\section{Acknowledgements}

The PRAEGNANT network is supported by grants from Novartis and Pfizer. The authors are grateful to Michael Robertson for professional medical editing services.

\section{Compliance with Ethical Standards}

\section{Funding}

Research for this subproject was supported in part by the German Federal Ministry of Economic Affairs and Energy through the “Clinical Data Intelligence” grant (01MT14001E).

\section{Ethical Approval}

All procedures performed in studies involving human participants were in accordance with the ethical standards of the relevant ethics committees, institutional review boards, good clinical prac- tise (GCP) and with the 1964 Helsinki declaration and its later amendments or comparable ethical standards.

\section{Informed Consent}

Informed consent was obtained from all individual participants included in the study.

\section{Conflict of Interest}

There do not appear to be any issues involving a potentially lower recruitment rate when electronic questionnaires are offered. All others authors declare that they have no conflicts of interest.

\section{References}

[1] Cardoso F, van't Veer LJ, Bogaerts J et al. 70-gene signature as an aid to treatment decisions in early-stage breast cancer. N Engl J Med 2016; 375: $717-729$

[2] Sparano JA, Gray RJ, Makower DF et al. Prospective validation of a 21gene expression assay in breast cancer. N Engl J Med 2015; 373: 20052014

[3] Schneeweiss A, Ruckhaberle E, Huober J. Chemotherapy for metastatic breast cancer - an anachronism in the era of personalised and targeted oncological therapy? Geburtsh Frauenheilk 2015; 75: 574-583

[4] Baselga J, Campone M, Piccart M et al. Everolimus in postmenopausal hormone-receptor-positive advanced breast cancer. N Engl J Med 2012; 366: 520-529

[5] Bendell JC, Rodon J, Burris HA et al. Phase I, dose-escalation study of BKM120, an oral pan-Class I PI3K inhibitor, in patients with advanced solid tumors. J Clin Oncol 2012; 30: 282-290

[6] Dieterich M, Angres ], Stubert ] et al. Patient-reported outcomes in implant-based breast reconstruction alone or in combination with a titanium-coated polypropylene mesh - a detailed analysis of the BREAST-Q and overview of the literature. Geburtsh Frauenheilk 2015; 75: 692-701

[7] Siedentopf F, Utz-Billing I, Gairing $S$ et al. Yoga for patients with early breast cancer and its impact on quality of life - a randomized controlled trial. Geburtsh Frauenheilk 2013; 73: 311-317

[8] Reilly CM, Bruner DW, Mitchell SA et al. A literature synthesis of symptom prevalence and severity in persons receiving active cancer treatment. Support Care Cancer 2013; 21: 1525-1550

[9] Fromme EK, Eilers KM, Mori $\mathrm{M}$ et al. How accurate is clinician reporting of chemotherapy adverse effects? A comparison with patient-reported symptoms from the Quality-of-Life Questionnaire C30. J Clin Oncol 2004; $22: 3485-3490$

[10] Lux MP, Maass N, Schuetz F et al. Breast cancer 2013 - interpretation of new and known data. Geburtsh Frauenheilk 2013; 73: 584-598

[11] Basch E. Patient-reported outcomes in drug safety evaluation. Ann Oncol 2009; 20: 1905-1906

[12] Basch E, Jia X, Heller $G$ et al. Adverse symptom event reporting by patients vs. clinicians: relationships with clinical outcomes. J Natl Cancer Inst 2009; 101: 1624-1632

[13] U. S. Department of Health and Human Services FDA Center for Drug Evaluation and Research; U. S. Department of Health and Human Services FDA Center for Biologics Evaluation and Research; U. S. Department of Health and Human Services FDA Center for Devices and Radiological Health. Guidance for industry: patient-reported outcome measures: use in medical product development to support labeling claims: draft guidance. Health Qual Life Outcomes 2006; 4: 79 
[14] Wuerstlein R, Kirkovits T, Drewes C et al. eHealth in modern breast cancer treatment: new possibilities in communication between patients, doctors and nursing staff. In: Proceedings of the Thirty-Seventh Annual CTRC-AACR San Antonio Breast Cancer Symposium: 2014 Dec 9-13; San Antonio, TX Philadelphia (PA): AACR. Cancer Res 2015; 75 (9 Suppl.): Abstract nr P2-10-05

[15] Willke RJ, Burke LB, Erickson P. Measuring treatment impact: a review of patient-reported outcomes and other efficacy endpoints in approved product labels. Control Clin Trials 2004; 25: 535-552

[16] Szende A, Leidy NK, Revicki D. Health-related quality of life and other patient-reported outcomes in the European centralized drug regulatory process: a review of guidance documents and performed authorizations of medicinal products 1995 to 2003. Value Health 2005; 8: 534-548

[17] Abernethy AP, Herndon JE 2nd, Wheeler JL et al. Feasibility and acceptability to patients of a longitudinal system for evaluating cancer-related symptoms and quality of life: pilot study of an e/Tablet data-collection system in academic oncology. J Pain Symptom Manage 2009; 37 : 1027-1038

[18] Basch E. New frontiers in patient-reported outcomes: adverse event reporting, comparative effectiveness, and quality assessment. Annu Rev Med 2014; 65: 307-317

[19] Dueck AC, Mendoza TR, Mitchell SA et al. Validity and reliability of the US National Cancer Institute's Patient-Reported Outcomes version of the Common Terminology Criteria for Adverse Events (PRO-CTCAE). JAMA Oncol 2015; 1: 1051-1059

[20] Basch E, lasonos A, Barz A et al. Long-term toxicity monitoring via electronic patient-reported outcomes in patients receiving chemotherapy. J Clin Oncol 2007; 25: 5374-5380

[21] Judson T], Bennett AV, Rogak LJ et al. Feasibility of long-term patient selfreporting of toxicities from home via the Internet during routine chemotherapy. J Clin Oncol 2013; 31: 2580-2585

[22] Graf J, Simoes E, Wisslicen $\mathrm{K}$ et al. Willingness of patients with breast cancer in the adjuvant and metastatic setting to use electronic surveys (ePRO) depends on sociodemographic factors, health-related quality of life, disease status and computer skills. Geburtsh Frauenheilk 2016; 76: $535-541$

[23] Di Maio M, Basch E, Bryce ] et al. Patient-reported outcomes in the evaluation of toxicity of anticancer treatments. Nat Rev Clin Oncol 2016; 13 : 319-325

[24] Fasching PA, Brucker SY, Fehm TN et al. Biomarkers in patients with metastatic breast cancer and the PRAEGNANT Study Network. Geburtsh Frauenheilk 2015; 75: 41-50

[25] Hein A, Gass P, Walter CB et al. Computerized patient identification for the EMBRACA clinical trial using real-time data from the PRAEGNANT network for metastatic breast cancer patients. Breast Cancer Res Treat 2016; 158: 59-65

[26] The IPAQ group at Karolinska Institute Stockholm. Guidelines for data processing and analysis of the International Physical Activity Questionnaire (IPAQ). 2005. Online: https://sites.google.com/site/theipaq/ scoring-protocol; last access: 01.09.2016
[27] Axen I, Bodin L, Bergstrom G et al. The use of weekly text messaging over 6 months was a feasible method for monitoring the clinical course of low back pain in patients seeking chiropractic care. J Clin Epidemiol 2012; 65: 454-461

[28] Registered Nurses' Association of Ontario (RNAO). The Nursing and eHealth Project. Online: http://rnao.ca/ehealth; last access: 16.09.2016

[29] e-Health Nurses Network. Online: http://www.ehealthnurses.org.uk/; last access: 16.09.2016

[30] International Council of Nurses (ICN) eHealth Programme encompasses. Online: http://www.icn.ch/what-we-do/ehealth/; last access: 16.09.2016

[31] Schaffeler N, Pfeiffer K, Grischke EM et al. [Acceptance and reliability of an electronic psychooncological screening of patients with breast cancer: a randomized controlled study]. Psychotherapie, Psychosomatik, medizinische Psychologie 2013; 63: 374-380

[32] Coons S], Gwaltney C], Hays RD et al. Recommendations on evidence needed to support measurement equivalence between electronic and paper-based patient-reported outcome (PRO) measures: ISPOR ePRO Good Research Practices Task Force report. Value Health 2009; 12: 419-429

[33] Jehn CF, Flath B, Strux A et al. Influence of age, performance status, cancer activity, and IL-6 on anxiety and depression in patients with metastatic breast cancer. Breast Cancer Res Treat 2012; 136: 789-794

[34] Li D, Zhang DJ, Shao J] et al. A meta-analysis of the prevalence of depressive symptoms in Chinese older adults. Arch Gerontol Geriatr 2014; 58: 1-9

[35] Fernandez-Alonso L, Munoz-Garcia D, La Touche R. The level of physical activity affects the health of older adults despite being active. J Exerc Rehabil 2016; 12: 194-201

[36] Wanner M, Martin BW, Autenrieth CS et al. Associations between domains of physical activity, sitting time, and different measures of overweight and obesity. Preventive Medicine Reports 2016; 3: 177-184

[37] Dabrowska J, Dabrowska-Galas M, Naworska B et al. The role of physical activity in preventing obesity in midlife women. Prz Menopauzalny 2015; 14: 13-19

[38] Ruiz-Casado A, Alejo LB, Santos-Lozano A et al. Validity of the Physical Activity Questionnaires IPAQ-SF and GPAQ for cancer survivors: insights from a Spanish cohort. Int J Sports Med 2016; doi:10.1055/s-0042103967

[39] Hurtig-Wennlof A, Hagstromer M, Olsson LA. The International Physical Activity Questionnaire modified for the elderly: aspects of validity and feasibility. Public Health Nutr 2010; 13: 1847-1854

[40] Forsen L, Loland NW, Vuillemin A et al. Self-administered physical activity questionnaires for the elderly: a systematic review of measurement properties. Sports Med 2010; 40: 601-623 